\title{
Functional Foods, Health Benefits and Health Claims
}

\author{
By Stavroula Malla ${ }^{*}$ \\ Jill E. Hobbs ${ }^{\dagger}$ \\ Eric Kofi Sogaht
}

\begin{abstract}
The growing burden of health care cost remains a key policy issue. The potential effects on public health care costs of increasing the consumption of functional foods in diets through the ability to make new health claims is of major policy relevance. However, there are also multiple potential market failures associated with functional foods. This paper outlines a number of issues and market failures related to the consumption and production of healthier foods, including labelling of health claims. The paper also evaluates the potential magnitude of health-related cost savings by allowing new health claims, using the example of "soluble fibre from certain foods (barley and psyllium) and coronary heart disease" and "soy protein and coronary heart disease" health claims. The preliminary results suggest that an increased consumption of functional food due to new health claims could result in significant health cost savings. Despite this, the existence of production and consumption externalities could result in an inefficient outcome rather than the socially optimal level of consumption of foods with health benefits. Policy implications are discussed.
\end{abstract}

\section{Introduction}

The World Health Organization identifies nutrition as a significant and manageable determinant of chronic disease (WHO, 2002). Scientific evidence and a growing awareness of the correlation between diet and health, coupled with sedentary lifestyles, an aging population, and ever increasing healthcare costs have driven the interest in healthier food products (e.g., Malla et al 2013a, 2013b). These products include functional foods and natural health products (also known as nutraceuticals or dietary supplements) with positive health benefits to consumers ${ }^{1}$.

\footnotetext{
*Associate Professor, University of Lethbridge, Canada.

†Professor, University of Saskatchewan, Canada.

${ }^{\star}$ Research Assistant, University of Lethbridge, Canada.

${ }^{1}$ Health Canada (1998) defines functional foods as: "a functional food is similar in appearance to, or may be, a conventional food, that is consumed as part of a usual diet, and is
} 
Existing literature suggests that the development of credible health claims on functional food can produce benefits in the form of improved health, health cost reductions and a facilitation of market growth through international trade (e.g., West and Larue 2004, Stein and Rodriguez- Cerezo 2008, ADA 2004, IFIC 2009, IFT 2005, Siegrist, Stampfli and Kastenholz 2008, Herath, Cranfield, Henson and Sparling 2008, Hawkes 2004, Bech-Larsen and Scholderer 2007, Henson et al 2010) ${ }^{1,2}$. However, the literature also suggests that self-interested individual behaviour often leads to an economically inefficient allocation of resources and in turn generates a need for government intervention to correct "market-failures" (e.g., Arrow 1969, Bator 1958, Stiglitz 1989, Wolf 1987, 1988). The existence of "market" failures could lead to socially inefficient outcomes in the form of sub-optimal consumption of food with health benefits.

The objectives of this study are: (i) to present a number of issues related to healthier/functional food markets, and (ii) to provide an assessment of potential health cost savings by allowing new health claims on food products. Specifically, the study outlines the market failure arguments pertaining to the consumption and production of functional foods, including labeling of health claims. Furthermore, the study estimates the potential benefits from savings in health-related costs of allowing disease risk reduction health claims on foods containing soluble fibre (specifically, barley and psyllium), as well as on soy protein. ${ }^{3}$.

The growing burden of health care costs remains a key policy issue in many countries. Added to these direct costs of illness are the indirect costs of diet-related diseases (lost productivity, forgone income, etc). The potential effects on direct and indirect health-related costs of increasing the consumption of functional foods through allowing new health claims is of major policy relevance. Potential "market failures" could also generate the need for government intervention to correct the inefficiencies and are discussed in the context of policy implications and recommendations.

demonstrated to have physiological benefits and/or reduce the risk of chronic disease beyond basic nutritional functions".

Nutraceuticals are isolated or purified nutrients sold in medicinal form (e.g. pill form, or more broadly, in doses) and have specific health benefits (Health Canada 1998). Natural health products are a group of products which include most nutraceuticals but also homeopathic and traditional medicines (Walji \& Boon 2008).

${ }^{1} \mathrm{~A}$ health claim on food is "any representation in labelling and advertising that states, suggests, or implies that a relation exists between the consumption of foods or food constituents and health" (Health Canada 2010).

${ }^{2}$ For a more detailed discussion of functional food and natural health products, see our reports "Functional Foods and Natural Health Products Regulations in Canada and Around the World: Nutrition Labels and Health Claims" (2013b) and "Assessing the Functional Foods and Natural Health Products Industry: A Comparative Overview and Literature Review" (2013a), which are available from the Canadian Agricultural Innovation and Regulation Network (CAIRN) at http://www.ag-innovation.usask.ca/.

"Psyllium products and blood cholesterol lowering (2011)" and "Barley products and blood cholesterol lowering (2012)" claims have been recently approved in Canada; while the "soy protein and coronary heart disease" claim is still under consideration in Canada, but already permitted in countries like the U.S, Sweden, Brazil and U.K. 


\section{Market Failures: Consumption and Production of Functional Foods}

There are different types of potential market failures related to the consumption and production of functional foods. The sources of these market failures are: negative externalities and information asymmetry in consumption and multiple positive externalities (spillovers) in the production of functional foods.

Figure 1. Market Failures

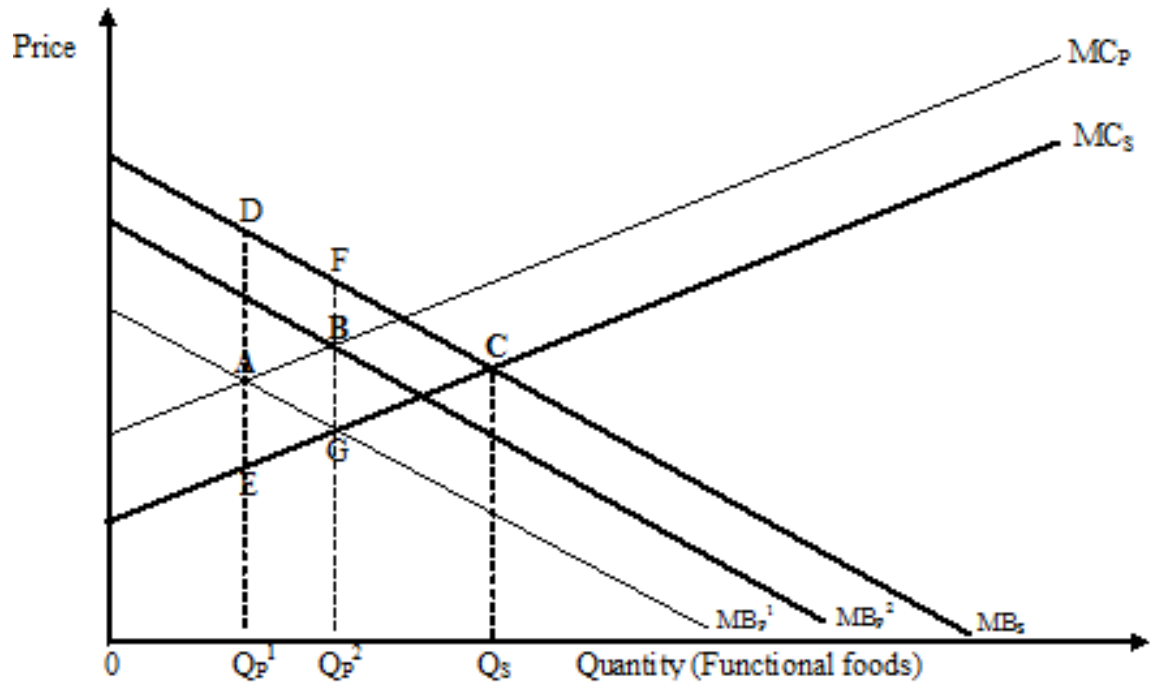

Specifically, the first form of consumption-related market failure arises from information asymmetry regarding credibly signaling the health benefits inherent in functional foods. The potential health benefit from a functional food is a credence attribute and as such cannot be identified by consumers without labeling. To be effective, labels must be credible. Usually governments intervene in the market for functional foods to regulate the types of health claims that can be made. The second form of consumption-related market failure is the negative externality generated by the costs of ill health not being fully borne by the individual. This occurs for publicly funded health care systems but also for private health insurance markets. The market failure arises when a portion of the financial cost of illness is borne by a third party (taxpayers or the insurer). If credible, labeling health claims addresses the market failure due to information asymmetry, but does not address the negative consumption externality. Ultimately consumers must still choose to consume these foods.

In addition, a potential production-related market failure arises due to technology spillover. This is a type of positive externality that exists when a firm's innovation or research into a new technology contributes to reducing the research costs of other firms, hence benefiting society as a whole. If other firms can easily 'free-ride' on the R\&D investments of the innovating firm, there will be sub-optimal levels of investment in foods with health benefits. In the case of 
functional foods, firms in many countries including Canada use 'trade secrets' extensively instead of 'patent' as a means to protect their research investments. The use of this form of weaker intellectual property rights (IPRs) protection does not allow firms to capture all of the rents from their investment and affects decisions to undertake R\&D.

Furthermore, the registration process for novel foods and the approval process for new health claims can introduce an element of market failure. Specifically, novel foods must undergo a registration process in many countries including Canada. ${ }^{1}$ Once a food receives novel food approval, other firms with the same nutrient or nutrients can all enter the market at the same time. Only one firm has to apply for and bear the costs of novel food approval and registration. Therefore, there are significant spillover benefits that accrue to firms that do not bear the novel food registration costs. Since the benefits of pursuing a novel food through the approval process accrue to others in addition to the innovating firm, there will be sub-optimal levels of resources allocated to new product approvals. This is a form of market failure.

With respect to health claims, there are in general two types of health claims: generic and product specific. Generic claims create a free rider problem and positive spillover effect because many firms can benefit but only one firm has to go through the application process to get approval for a new claim. With generic claims, anyone can use the claim after it is approved. ${ }^{2}$ In the presence of significant free-rider problems there is a disincentive for firms to invest in pursuing approvals for new generic health claims.

The "market" failures associated with the consumption and production of functional foods are presented in Figure 1. The private marginal benefit curve without labeling/health claims is denoted $\mathrm{MB}_{\mathrm{P}}{ }^{1}$; while the private marginal benefit curve with labeling/health claims is denoted $\mathrm{MB}_{\mathrm{P}}{ }^{2}$. The social marginal benefit curve associated with the consumption of functional foods is labeled $\mathrm{MB}_{\mathrm{S}}$. The social marginal benefit is greater than the private marginal benefit due to the asymmetry of information issue and health cost externality described above. Similarly, $\mathrm{MC}_{\mathrm{P}}$ is the private marginal cost curve and $\mathrm{MC}_{\mathrm{S}}$ is the social marginal cost curve. The social marginal cost is less than the private marginal cost due to the presence of production externalities as described above.

The intersection of the private marginal benefit curve and the private marginal cost curve determines the optimal quantity of functional food. When consumers are not informed about the positive health effects of functional food consumption and also under-consume healthier foods due to health cost externalities, the private equilibrium is determined at point $\mathbf{A}$ (corresponding output level $\mathrm{Q}_{\mathrm{P}}{ }^{1}$ ); while when consumers are informed but do not bear the full costs of poor health outcomes, then the private equilibrium is determined at point B (corresponding output level $\mathrm{Q}_{\mathrm{P}}{ }^{2}$ ).

\footnotetext{
${ }^{1}$ Novel foods are most commonly categorized as foods not previously used by humans or with no history of use; sometimes also include food products that are genetically engineered or derived through biotechnology. They may or may not include functional foods

${ }^{2}$ Product specific claims are used only by products that undergo a registration process for a claim that specifies a relationship between the food or food constituent and a health benefit.
} 
The socially optimal equilibrium is determined at point $\mathrm{C}$, where the marginal social cost is equal to the marginal social benefit. The socially optimal output level $\left(Q_{S}\right)$ is higher than the private optimal output levels $\left(Q_{P}{ }^{1}\right.$, $\left.\mathrm{Q}_{\mathrm{P}}{ }^{2}\right)$. Labelling is expected to address one aspect of the consumption-related market failure (information asymmetry) but it would not lead to the socially optimal consumption level. Consequently, positive externalities (spillovers) in production, as well as negative externalities and information asymmetry in consumption, lead markets to produce/consume a smaller quantity than is socially desirable. This provides a rationale for government intervention to correct these market failures. A particularly important policy that addresses one of these market failures is the regulation of health claims on food.

\section{Potential Health Care Cost Savings by Allowing New Health Claims}

The potential magnitude of health-related cost savings in Canada from allowing new health claims is assessed in this section, using the example of "soluble fibre from certain foods (barley and psyllium) and CHD (coronary heart disease)" and "soy protein and CHD" health claims. The method used in the analysis is a variation of the cost of illness approach (COI). Each stage in the estimations is supported by scientific evidence from the health sciences and medical/nutrition literature, official government publications and/or statistical data.

The analysis consists of four stages and draws upon Malla, Hobbs and Perger (2007). ${ }^{1}$ The first stage estimates the potential increase in daily soluble fibre and soy protein intake from consumption of barley, psyllium and soy products due to the approval of health claims linking consumption of these products to reduced risk of CHD. Recall that health claims for soluble fibre in barley and psyllium were approved in Canada in 2012, while a health claim linking the consumption of soy protein and reduced risk of CHD is still under consideration. Based on current consumption levels (Statistics Canada 2009), it is estimated that the daily soluble fibre intake (from barley and psyllium via cereal products) per person in Canada is $0.24 \mathrm{~g}$; while the daily soy protein intake per person in Canada is $6.45 \mathrm{~g}$. From the estimation of the current daily soluble fibre intake, it is assumed that ability to label these foods with a health claim leads to a $50 \%$ increase in soluble fibre intake, which translated into a $0.12 \mathrm{~g} /$ day increase for every Canadian. In the case of soy protein, it is also assumed that a 50\% increase in soy protein intake would arise if a health claim were approved which, given the estimation of the current daily soy protein intake, would result in a $3.22 \mathrm{~g} /$ day increase in soy protein intake for every Canadian.

The second stage calculates the change in cholesterol levels due to increased soluble fibre and soy protein consumption. A meta-analysis of scientific medical/nutrition literature (controlled diets) that measures the effect on cholesterol levels (LDL) of increased soluble fibre or soy protein intake

\footnotetext{
${ }^{1}$ A detailed description of the calculations is available from the authors upon request.
} 
reveals (on average) the following assumed relationships (e.g., Behall et al 2004, Matthan 2007, Larkin et al 2009, Sartore et al 2009, Lerman et al 2010, Solà et al 2010) ${ }^{1}$ :

- a $1 \mathrm{~g}$ increase in soluble fibre reduces LDL (bad cholesterol) by $1.55 \%$;

- a $1 \mathrm{~g}$ increase in soy protein reduces LDL (bad cholesterol) by $0.37 \%$.

Using the above relationships and given the $0.12 \mathrm{~g} /$ day increase in soluble fibre consumption due to health claims [stage 1], we assume that LDL cholesterol levels would be reduced by $0.19 \%(0.12 \mathrm{~g} * 1.55)$ due to increased consumption of soluble fibre. While in a case of soy protein, using the above relationship, LDL cholesterol levels would be reduced by $1.19 \%$ on average given the estimated $3.22 \mathrm{~g} /$ day increase in soy protein consumption due to health claims [stage 1].

The third stage calculates the coronary heart disease (CHD) risk reduction due to changes in the cholesterol profile of the population. A comprehensive review of scientific literature measuring the effect of changes in cholesterol levels/ratio on CHD was conducted. The US National Cholesterol Education Expert Panel (Expert Panel, 2002) has concluded the following:

- 'a $1 \%$ reduction in LDL cholesterol levels reduces the risk of CHD by $2.2 \%$.

Based on the above relationship, and given the change in cholesterol level by $0.19 \%$ due to increased consumption of soluble fibre [stage 2], the CHD risk would be reduced by $0.41 \%$ in the case of a health claim related to soluble fibre. Similarly for the soy protein health claim, CHD risk would be reduced by $2.62 \%$ due to the change in cholesterol level of $1.19 \%$ [stage 2].

Finally, the fourth stage calculates the health cost changes due to CHD risk reduction. The simplest cost of illness (COI) approach assumes that a 1\% drop in the incidence of the disease, in the long run, will result in a $1 \%$ decrease in the COI (Malla et al., 2007). Hence, we assume a 1:1 relationship between the reduction in disease incidence and the reduction in health costs (both direct and indirect costs):

- 'a $1 \%$ reduction in CHD risk reduces CHD cost by $1 \%$ '

It is estimated that heart disease contributed approximately $\$ 22.2$ billion in health-related costs (direct and indirect costs) in Canada in 2000 (Public Health Agency of Canada, 2009). Indeed, cardiovascular disease (CVD) had the second highest total cost among all diagnostic categories. Based on an assumed 1/1 ratio between the incidence of CHD and the resulting costs, and

\footnotetext{
${ }^{1}$ Details of the meta analysis and sources of these assumptions are available from the authors.
} 
given the estimated reduction of CHD risk by $0.41 \%$ [stage 3], then the extent of annual health-related cost savings is $\$ 90.84$ million annually due to increased consumption of soluble fibre ${ }^{1}$. Similarly, the increased consumption of soy protein results in health cost savings equal to $\$ 582.40$ million annually (given the $2.62 \%$ reduction in the CHD risk [stage 3 ]).

To sum up, allowing health claims on soluble fibre in Canada is expected to increase consumption on average by $0.12 \mathrm{~g} /$ day per person, which reduces LDL cholesterol levels by $0.19 \%$ and in turn reduces CHD risk by $0.14 \%$. This would result in annual estimated savings in direct and indirect costs of poor health (CHD) of $\$ 90.84$ million annually. Similarly, allowing health claims on soy protein is expected to increase consumption on average by $3.22 \mathrm{~g} / \mathrm{day}$ per person, which reduces LDL cholesterol levels by $1.19 \%$ and in turn reduces CHD risk by $2.62 \%$. This would result in health cost savings of $\$ 582.40$ million annually.

\section{Conclusion}

The growing burden of health-related costs remains a concern in Canada and other countries, particularly those with publicly funded health care systems. The potential effects on the costs of poor health to society of encouraging increased consumption of healthier foods through allowing new credible health claims is of policy relevance. Using the example of "soluble fibre from certain foods (barley and psyllium) and CHD" and "soy protein and CHD" health claims, the paper estimates the potential health cost savings associated with increased consumption of soluble fibre and soy protein to be equal to $\$ 90.84$ and $\$ 582.40$ million respectively per year. Hence, an increased consumption of functional food due to new health claims could result in nontrivial health cost savings and increase economic welfare. While health claims relating consumption of soluble fibre in products containing barley and pysllium to reduced risks of CHD are now permitted in Canada, health claims linking the consumption of soy protein and CHD risk have not yet been approved. It is worth noting that the estimated annual savings in health-related costs for a soluble fibre claim, while in the tens of millions of dollars, are dwarfed in magnitude by the potential savings in health-related costs from a soy protein-CHD risk reduction claim. In a system where it often takes years for a new health claim to be approved, it may be worthwhile policy makers considering the magnitude of the potential societal benefits when prioritizing health claims approval processes.

Furthermore, there are a number of potential market failures related to the consumption and production of functional foods resulting in socially inefficient outcomes. Government intervention in the functional foods market may be justified to correct the inefficiencies. This intervention can take multiple forms such as: educating consumers; fostering investment in R\&D; tax incentives and

${ }^{1}$ Total change in CHD cost is calculated by multiplying the total annual CHD cost with the percentage change of the CHD cost. 
subsidies (e.g., providing tax breaks); a period of exclusivity regarding health claims; patents incentives; allowing product specific health claims; reform in the regulatory environment for health claims and the novel food registration process. These are fruitful topics for further research.

\section{References}

American Dietetic Association (ADA) (2004). 'Position of the American Dietetic Association: Functional foods.' Journal of the American Dietetic Association 104 (5): 814-826.

Arrow, K. J. (1969). 'The Organization of economic activity: issues pertinent to the choice of market versus non-market allocations.' in Analysis and Evaluation of Public Expenditures: The PPP System, Volume 1, pp. 47-64. Washington, D.C.

Bator, F. M. (1958). 'The anatomy of market failure.' Quarterly Journal of Economics 72(3): 351-379.

Bech-Larsen T. and J. Scholderer (2007). 'Functional foods in Europe: consumer research, market experiences and regulatory aspects.' Trends in Food Science \& Technology 18:231-234.

Behall KM, D.J.Scholfield and J. Hallfrisch (2004). 'Lipids significantly reduced by diets containing barley in moderately hypercholesterolemic men.' American Journal of Clinical Nutrition 23(1):55-62.

Expert Panel of Detection, Evaluation and Treatment of High Blood Cholesterol in Adults (Adult Treatment Panel III) (2002). Final Report on the National Cholesterol Education Program Expert Panel on Detection, Evaluation and Treatment of High Blood Cholesterol in Adults. National Institutes of Health. NIH Publication No. 02-5215.

Hawkes C. (2004). 'Nutrition labels and health claims: the global regulatory environment.' World Health Organization, LC/NLM classification: QU 145. (http://whqlibdoc.who.int/ publications/2004/9241591714.pdf).

Health Canada (1998). Nutraceuticals/Functional Foods and Health Claims on Foods. (http://www.hc-sc.gc.ca/fn-an/label-etiquet/claims-reclam/nutra-funct foods-nutra-fonct_aliment-eng.php\#tphp).

Health Canada (2010). Food and nutrition - Health Claims. ( http://www.hcsc.gc.ca/fn-an/label-etiquet/claims-reclam/index-eng.php).

Henson S., J. Cranfield, and D. Herath (2010). 'Understanding consumer receptivity towards foods and non-prescription pills.' International Journal of Consumer Studies 34 (1): 28-37.

Herath D., J. Cranfield, S. Henson, and D. Sparling (2008). 'Firm, market, and regulatory factors influencing innovation and commercialization in Canada's functional food and nutraceutical sector.' Agribusiness 24 (2): 207-230.

Institute of Food Technologist (IFT) (2005). Functional foods: Opportunities and challenges, IFT Expert Panel Report.

International Food Information Council (IFIC) (2009). Background on functional foods (http://www.foodinsight.org/Resources/Detail.aspx?topic=Background on Functional Foods).

Larkin T.A., L.B. Astheimer and W.E. Price (2009). 'Dietary combination of soy with a probiotic or prebiotic food significantly reduces total and LDL cholesterol in mildly hypercholesterolaemic subjects.' European Journal of Clinical Nutrition 63(2):238-45. 
Lerman R.H., D.M. Minich, G. Darland, J.J. Lamb, J.L. Chang, A. Hsi, J.S. Bland and M.L. Tripp (2010). 'Subjects with elevated LDL cholesterol and metabolic syndrome benefit from supplementation with soy protein, phytosterols, hops rho iso-alpha acids, and acacia nilotica proanthocyanidins.' Journal of Clinical Lipidology 4(1):59-68.

Malla, S., J.E. Hobbs and S. Perger (2007). 'Valuing the health benefits of a novel functional food.' Canadian Journal of Agricultural Economics 55(1):115-136.

Public Health Agency of Canada (2009). Tracking heart disease and stroke in Canada. (http://www.phac-aspc.gc.ca/ Cat: HP32-3/2009E ISBN: 978-1-10012541-1).

Malla, S., J.E. Hobbs, and E. Sogah (2013b). Functional foods and natural health products regulations in Canada and around the world: Nutrition labels and health claims. Canadian Agricultural Innovation and Regulation Network (CAIRN), Saskatoon, SK. (http://www.ag-innovation.usask.ca/).

Malla, S., J.E. Hobbs, E. Sogah, and M. T. Yeung (2013a). Assessing the functional foods and natural health products industry: A comparative overview and literature review. Canadian Agricultural Innovation and Regulation Network (CAIRN), Saskatoon, SK (http://www.ag-innovation.usask.ca/).

Matthan N.R., S.M. Jalbert, L.M. Ausman, J.T. Kuvin, R.H. Karas and A.H. Lichtenstein_(2007). 'Effect of soy protein from differently processed products on cardiovascular disease risk factors and vascular endothelial function in hypercholesterolemic subjects.' American Journal of Clinical Nutrition 85(4):960-6.

Sartore G., R. Reitano, A. Barison, P. Magnanini, C. Cosma, S. Burlina, E. Manzato, D. Fedele and A. Lapolla (2009). The effects of psyllium on lipoproteins in type II diabetic patients. European Journal of Clinical Nutrition. 63(10):1269-71.

Siegrist M., N. Stampfli and H. Kastenholz (2008). 'Consumers' willingness to buy functional foods: The influence of carrier, benefit and trust.' Appetite 51:526529.

Solà R., E. Bruckert, R.M. Valls, S. Narejos, X. Luque, M. Castro-Cabezas, G. Doménech, F. Torres, M. Heras, X. Farrés, J.V. Vaquer, J.M. Martínez, M.C. Almaraz and A. Anguera_(2010). 'Soluble fibre (Plantago ovata husk) reduces plasma low-density lipoprotein (LDL) cholesterol, triglycerides, insulin, oxidised LDL and systolic blood pressure in hypercholesterolaemic patients: A randomised trial.' Atherosclerosis 211(2):630-7.

Statistic Canada (2009). Table 001-0041 - Supply and Disposition of Grains in Canada as of March 31, July 31, August 31 (soybeans only) and December 31, 3 times per year (metric tonnes), CANSIM (database), Using E-STAT (distributor). (http://estat.statcan.gc.ca/cgi-win/cnsmcgi.exe?Lang=E\&amp;EST-Fi=EStat/Eng lish/CII 1-eng.htm).

Stein J. A., and E. Rodriguez-Cerezo (2008). Functional food in the European Union. Institute for Prospective Technological Studies (IPTS), Technical report series EUR $23380 \mathrm{EN}-2008$.

Stiglitz, J. E. (1989). 'Markets, market failures, and development.' American Economic Review 79(2):197-203.

Walji, R.and H. Boon (2008). 'Natural health products regulations: perceptions and impacts.' Food Science and Technology 19: 494-497.

West G. E. and B. Larue (2004). 'Profiling consumer trend-setters in the Canadian healthy-foods market.' Current Agriculture Food and Resource Issues 5: 65-82.

Wolf, C. (1987). 'Market and non-market failures: Comparison and assessment.' Journal of Public Policy 7(I): 43-70. 
Vol. 1, No. $1 \quad$ Malla et al: Functional Foods, Health Benefits and Health Claims

Wolf, C. (1988, $1^{\text {st }}$ edition; 1993, $2^{\text {nd }}$ edition). Markets or Governments: Choosing Between Imperfect Alternatives. MIT Press, Cambridge, Massachusetts.

World Health Organization (2002). Globalization, Diets and Noncommunicable Diseases. WHO Library Cataloguing-in-Publication Data. (http://www.who.int/ hpr/NPH/docs/globalization.diet.and.ncds.pdf). 